\title{
Bridging the Gap between Accounting Students and the Profession: A Case Study
}

\author{
Susan Lightweis ${ }^{1}$ \\ ${ }^{1}$ School of Business, Strayer University, Raleigh, North Carolina, USA \\ Correspondence: Susan Lightweis, School of Business, Strayer University, 8701 Wadford Drive, Raleigh, North \\ Carolina, USA. Tel: 1-919-301-6524. E-mail: susan.lightweis@strayer.edu
}

Received: August 11, 2014

Accepted: August 27, $2014 \quad$ Online Published: September 20, 2014

doi:10.5539/hes.v4n5p18

URL: http://dx.doi.org/10.5539/hes.v4n5p18

\begin{abstract}
This study addresses the gap between accounting educators and the profession. Research indicates accounting graduates are underprepared for this challenging career. The issue stems from accounting educators who only lecture and accounting students who memorize the information provided in these lectures. Accounting students need opportunities to build their professional skills through learning activities that mimic real-world situations. This qualitative study analyzes the perspectives of advanced accounting students before and after computer-assisted instruction to determine if they believe their critical thinking, communication and problem solving skills have improved. I conducted an analysis using an auditing simulation, semi-structured interviews before and after computer use, and reflective journals provided by advanced accounting students attending Central North Carolina universities. The auditing simulation introduced in the study created the opportunity for students to practice their knowledge of accounting and enhance their professional skills. The findings suggested students made a connection between concepts learned in course work and situations found in the accounting profession. The simulation built confidence in students and motivated them to learn more about enhancing skills necessary for the accounting profession. The evidence recommends accounting educators to use simulations as a supplemental learning tool in preparing accounting students for the profession. This study allows colleges, universities, and state accounting associations and societies to explore and conduct future research in using learning tools to enhance professional skills to bridge the gap between accounting students and the profession.
\end{abstract}

Keywords: accounting students, computer-assisted instruction, simulation game, critical thinking skills, communication skills, problem solving skills, professional skill set

\section{Introduction}

Many educators struggle with the pressures of preparing students with skills for the $21^{\text {st }}$ century workforce. The Common Core State Standards implementation in the K-12 environment stresses higher-level skills in all subject areas. With this implementation, K-12 teachers are held accountable for students to achieve certain skills and knowledge by the end of each school year. Colleges and universities are not held to the same rigorous standards, yet these higher education institutions will graduate students who will be required to have certain skills to be valuable contributors to their profession. For the accounting profession, research has stated there is a problem between what accounting students can contribute to their profession after graduation and what practitioners need (Guyette, 2008; Jonick, 1998; Lightweis, 2011; Smith, 2006). The problem is accounting courses are taught by lecture and not through learning activities which challenge students to understand what lies ahead in the accounting profession (Guyette, 2008; Jonick, 1998; Lightweis, 2011). Additionally, these learning activities can build upon the professional skill set necessary to be successful as a practitioner.

Certified Public Accounting (CPA) firms have had to change the way they conduct audits due to the financial scandals in the early part of the $21^{\text {st }}$ century. The Sarbanes-Oxley Act (SOX) of 2002 had mitigated financial scandals (Lightweis, 2011). However, with the arrest and conviction of Bernard Madoff in 2008, CPA firms continue to be on notice to conduct business with a high-level of professional responsibility the public and investors rely on (U.S. Securities \& Exchange Commission, 2009). If a CPA firm is found negligent in their professional responsibilities, fines and imprisonment can occur (Lightweis, 2011). CPA firms and other companies need to hire accountants who demonstrate critical thinking and problem-solving skills to solve growing and complex financial information (Damito \& Schmidgall, 2007; Guyette, 2008; Lightweis, 2011; 
Mastracchio, 2007). Additionally, accountants must demonstrate proficient communication skills to convey financial information necessary for companies to make strategic decisions regarding their future survival (Lightweis, 2011).

There continues to be a demand for accountants in an ever-changing global business environment (United States Department of Labor, 2009). Yet, accounting curriculums and pedagogical methods in colleges and universities are not keeping up with an evolving global business world, especially with adding learning experiences in accounting courses that mimic real-world situations accountants' face. The current use of lectures does not create learning opportunities for students to develop or enhance a professional skill set (Lightweis, 2011; Sharifi, McCombs, Fraser, \& McCabe, 2009). Ballantine, Duff, and Larres (2008) stated that many lectures focus on theories and concepts presented on CPA exams. Passing the CPA exams does not necessarily guarantee accounting graduates have the necessary professional skill set or have the critical thinking, communication, and problem-solving skills to be valuable contributors to CPA firms or other business organizations. Additionally, not all accounting graduates take or pass the CPA exams. Accounting graduates may be offered employment as bookkeepers, financial analysts, or tax examiners (Lightweis, 2011). These graduates will still need a professional skill set to meet the challenges of dealing and successfully managing complex financial information. There is a need for accounting educators to create learning opportunities for accounting students. These students need a venue to apply their knowledge in ambiguous financial situations as well as promote skill development necessary for the profession (Cheng, 2009; Coulson \& Thomson, 2006; Gammie, Gammie, \& Cargill, 2002; Hurt, 2007; Kavanaugh \& Drennan, 2008; Lightweis, 2011; Marriott, 2004; Morris \& Puttee, 2006; Sharifi, McCombs, Fraser, \& McCabe, 2009; Springer \& Borthick, 2007). There has been little research in higher education regarding skill development for accounting students (Ballantine, Duff, \& Larres, 2008; Lightweis, 2011). Smith (2006) reasoned not enough classroom time is devoted to skill development. Smith (2006) surveyed accounting educators, practitioners, and accounting graduates regarding effective teaching methods. While accounting educators favored lectures, accounting graduates and practitioners favored in-class experiential exercises. The use of learning tools in accounting courses to develop a professional skill set will assist accounting educators to change the way information is delivered to students. Accounting students should be provided with opportunities to apply their knowledge to real-world situations while still in school (Lightweis, 2011). If opportunities are not available for accounting students to use supplemental learning tools to develop or build on a professional skill set practitioners require, the gap between the accounting education and the profession will continue to be wide as ever (Guyette, 2008; Jonick, 1998; Kavanagh \& Drennan, 2008; Lightweis, 2011; Smith, 2006). This study analyzed advanced accounting students perspectives before and after computer-assisted instruction to enhance critical thinking, communication, and problem-solving skills. The findings from this study indicated students made a connection between the accounting knowledge learned in school and the expectations of what scenarios might occur in the profession. Additionally, the findings indicated a positive reaction to the simulation. This in turn motivated students to learn more about how to build their professional skills and learn more about the profession. This motivation created confidence in students' ability to be successful in the profession. Future use of learning tools that mimic real-world situations can assist accounting students to understand the expectations of the profession before they graduate.

\section{Rationale and Data Collection}

The study of advanced accounting students' perspectives was examined using the qualitative case study approach. The qualitative approach seeks an understanding of a phenomenon (Lightweis, 2011; Merriam, 1998). The phenomena studied were students' perspectives of their professional skill levels, which included critical thinking, communication, and problem-solving skills. The focus was the professional skill levels students believed they possessed at the time of the study (Lightweis, 2011). The study addressed the ongoing issue of accounting graduates not prepared to meet the challenges of the profession (Damito \& Schmidgall, 2007; Guyette, 2008; Kavanaugh \& Drennan, 2008; Lightweis, 2011; Sharifi, McCombs, Fraser, \& McCabe, 2009; Smith, 2006). Recommendations from several professional and governing organizations suggested accounting graduates develop the necessary skills in order to be successful practitioners (Accounting Education Change Commission, 1990; American Accounting Association, 1986; American Institute of Certified Public Accountants, 1998; International Federation of Accountants, 1996). Therefore, the study allows accounting educators to understand the importance of developing or enhancing a professional skill set for accounting students before they graduate. The use of computer-assisted instruction as a supplemental learning tool provides an opportunity for students to develop these skills as well as for accounting educators to undertake the responsibility in providing such opportunities to their students beyond just lecturing.

This study was not about any particular university, rather accounting student perspectives of their professional 
skill levels were key in understanding how accounting educators can use learning tools in courses to help students achieve professional skills necessary for the profession. This study used multiple sources of evidence. I used data collection procedures Yin (2009) stated to ensure validity in case study evidence. This study used semi-structured interviews, reflective journals, and an auditing simulation as sources of evidence. The auditing simulation was the computer-assisted instruction. The auditing simulation is called Real Audit ${ }^{\mathrm{TM}}$ and was developed by John A. Schatzel. Real Audit ${ }^{\mathrm{TM}}$ can be found on the website: http://realaudit.com. There are several versions instructors can purchase, depending upon how many modules and how in-depth instructors want their students to learn about the intricacies of an auditing environment. For this study, the Lite Version was chosen. In this version, the main modules were Planning, Accounts Receivable, and Fixed Assets. These modules were sufficient for the study as it allowed participants to navigate throughout these modules and be able to analyze sales, inventory, and accounts receivable numbers presented within the game. The game did provide a full set of financial statements in which participants made important decisions regarding the company. The simulation allowed students to be immersed in the auditing environment and be confronted with various situations which require a high-level of critical thinking, problem-solving, and decision-making. Additionally, the simulation allows participants to communicate with other staff auditors, audit manager, and the client's employees. There was a scoring mechanism which focused on the participant's experience and ability to control efficiency and the audit fee (Lightweis, 2011).

I purchased the Real Audit ${ }^{\mathrm{TM}}$ license and installed the simulation game onto a USB flash drive once each participant registered through the website. Using a USB flash drive allowed participants to work through the game at home on their own time. As participants enter and leave the game, a performance report was emailed to me indicating the time and activity spent in the simulation. A binder was provided to each participant with a set of instructions for entering the simulation and locating information necessary to respond to journal prompts. The journal prompt responses were written in reflective journals. These journals were provided to each participant during our first meeting. The reflective journals provided a source of evidence throughout the study. Furthermore, these journals provided a personal journey of experience and reflection necessary in understanding participant perspectives.

The third source of evidence was pre-computer and post-computer interviews. These interviews allowed participants to express their thoughts through open-ended, semi-structured responses (Lightweis, 2011; Yin, 2009). Merriam (1998) agreed and stated the responses are a way to understand the phenomenon through the perspectives provided throughout these interviews. The interviews were recorded and transcribed. Participants agreed to be recorded and were emailed the transcriptions for review and approval. The study took place during two months in the winter of 2011.

\subsection{Sample, Description and Goals}

A purposeful sample was selected for the study. The rationale with purposeful sampling is to provide an optimal amount of information that can be learned (Creswell, 2003; Lightweis, 2011). Additionally, the selection can provide information rich with thick descriptions regarding the phenomenon (Patton, 1987). The strategy used in purposeful sample for the study was maximum variation. The information derived from participants created patterns and themes regarding their professional skill levels in the study (Creswell, 2007; Lightweis, 2011; Patton, 1987). I posted flyers in a number of university student lounges in Central North Carolina. The first requirement for selection was participants who were in their senior year of a four-year accounting degree program. The second requirement was participants who had taken at least one auditing course. Also, those selected understood the time constraints of the study. The study would take place for two months during the winter of 2011. Therefore, the chosen participants would need time to meet with me twice for pre and postcomputer interviews and have entered and worked through the simulation requirements on at least four separate occasions to illicit learning experiences which could be documented. The qualitative case study involved three advanced accounting students. Each participant represented a case study to provide different perspectives of the issue. Although it may be argued that this was a small sample size, qualitative research seeks meaning, not numbers, to learn more about the phenomenon. Merriam (1998) agreed and stated there are no requirements for how many participants there should be in qualitative studies. The focus should be obtaining in-depth information on each participant (Lightweis, 2011; Patton, 1987).

The initial meetings were conducted separately. The meeting began with distributing the binder containing information for navigating the simulation. Additionally, I reviewed the information contained in the binders with each participant. The binder also contained the journal prompts which were to be written in a reflective journal. The journal notebook was provided to the participants during this meeting. Finally, a precomputer interview was conducted, which was approximately 30 minutes in length. After the precomputer interview, each participant 
registered their personal information (i.e., name, email address, login, and password) on the Real Audit ${ }^{\mathrm{TM}}$ web site. The simulation game was downloaded onto a USB flash drive.

All communication throughout the study was through email. I received emails from Real Audit ${ }^{\mathrm{TM}}$ on each participant. The information contained in this performance reports indicated time spent, what area the time was spent (i.e., which modules), experience rating, and score. In the beginning, one participant entered and exited the simulation multiple times. I emailed the participant asking if there was any trouble understanding the simulation requirements. The participant replied stating they finally figured out what to do. The other two participants had no issues entering and exiting the simulation. After two months, I received a number of performance reports from each participant. The participants entered and worked through the simulation requirements at least four times. I emailed each participant requesting a final meeting so I could interview them. During these final meetings, each participant returned their reflective journal to me, and a postcomputer interview was conducted. The interview lasted approximately 30 minutes.

The primary goal of the study was to learn about real-world accounting simulations and students' perspectives of what they have learned about themselves and their professional skill levels. As a former accountant, practicing certain processes multiple times throughout my career provided confidence in my ability to be a critical thinker and problem-solver. Additionally, my communication skills grew stronger, and I was more effective in communicating, both orally and in writing when faced with changing, challenging, and diverse clientele. As an accounting educator, I feel it is my responsibility to provide real-world learning opportunities in my accounting courses. Previous research regarding learning opportunities, especially implementing computer-assisted instruction in accounting courses, demonstrated positive results in students' skill levels in critical thinking, communication, and problem-solving (Esmond-Kiger \& Kirch, 2003; Handy, 2003; Townsend, 2006; Valentine \& Ivey, 2009). The results from this study allow accounting educators to research and implement learning tools that mimic real-world tasks and activities. This in turn can benefit accounting students' professional skill level development or enhancement before they graduate and enter a challenging profession.

\subsection{Evaluation of Results}

For this qualitative case study, multiple sources of evidence provided important information regarding participants' use of a real-world auditing simulation and how they felt about their professional skills before and after using this simulation game. The study addressed the issue of accounting educators who teach by lecture and accounting students who memorize information, but do not have the opportunity to demonstrate their knowledge and critical thinking, communication, and problem-solving skills through learning tools while attending school. The result has been accounting graduates who do not possess the necessary skill levels for the profession at the onset of their employment (Guyette, 2008; Jonick, 1998; Lightweis, 2011; Smith, 2006). In qualitative studies, researchers have to make sense of the data and be able to tell a story that is useful to others (Lightweis, 2011). The purpose of the study was to ascertain whether professional skill levels could be developed or enhanced through a learning tool that mimicked real-world accounting issues. Before the learning tool was introduced, a precomputer interview was conducted. The questions asked during the interview were open-ended, allowing participants to speak freely regarding the professional skills they believed they had. Table 1 provides the questions asked during this interview.

Table 1. Precomputer interview questions

Questions

Describe your plan of action you have in place before you start working on a school assignment.

You have a problem you are faced with. What different approaches do you use before tackling this problem?

Describe your biggest fear before your proceed to this computer program.

Describe how you feel regarding your critical thinking skills and ability to do accounting.

Describe how you feel regarding your communication skills. Why are communication skills important to the accounting profession?

Describe how you feel regarding your problem-solving skills and ability to do accounting.

Describe how you feel about learning new accounting concepts on your own.

Note. Adapted from "An Analysis of Advanced Accounting Students' Perspectives of their Professional Skills

Before and After Using Computer-Assisted Instruction,” by S. Lightweis, 2011, Pro Quest UMI, p. 121. 
The overall results of the precomputer interviews permitted a look into the world of three advanced accounting students' thoughts regarding the questions asked. All three participants stated they were very methodical in how they approach school assignments. This introductory question was to get participants comfortable in an interview setting, as well as prompting them to think about how they will approach the simulation game. Additionally, all participants stated they were methodical when tackling problems. The participants approach problems in a step-by-step manner, allowing time to analyze and seek alternative solutions before solving issues. When asked how fearful they are regarding the simulation game, all participants were afraid of failure, in one sense but eager to begin working through the simulation game and requirements. Finally, all participants believed they had decent critical thinking and problem-solving skills, but there was a mixed reaction in how they felt about their communication skills. The study separated communication skills into two elements. The first communication skill was oral, and the second communication skill was written. All participants felt good about their written communication skills as they had written many papers throughout their degree program. Only one participant felt they had good oral communication skills. The other two participants felt that their oral communication skills were a work in progress that improved each year they were in school. The lack of self-confidence with these participant's oral communication skills may be a contributing factor in attending accounting courses in which lectures do not allow students to express their understanding of concepts. Preparing homework assignments or taking exams does allow students to develop and enhance critical thinking and problem-solving skills, but does not allow students to work on oral communication skills. In having real-world projects or a simulation game, such as Real Audit ${ }^{\mathrm{TM}}$ as part of course work, accounting students are able to demonstrate their understanding of concepts not only through using their critical thinking and problem-solving skills but also using their communication skills as they interact with a computer program.

At the end of the precomputer interview, I distributed the binder and the reflective journal. I explained each section of the binder to participants and where to locate the journal prompts. Additionally, I explained how to use the reflective journal. Once the simulation game was successfully downloaded onto each participant's USB flash drive, the participants went home to work through the simulation requirements and respond to the journal prompts in their reflective journal. Table 2 represents the instructions provided in the binders for participants to complete.

Table 2. Simulation and reflective journal prompts

\begin{tabular}{ll}
\hline Section & Journal Prompts \\
\hline Start the Simulation & After you log in, read and respond (by following the \\
clues that allow you to proceed with the discussion \\
between yourself and the Audit Manager) to the initial \\
instructions from the Audit Manager. It is perfectly OK \\
to go back and forth until you are comfortable with \\
how the discussion is going. \\
Do the game tutorial. \\
Find the virtual desk (with some help from the \\
receptionist).
\end{tabular}

Inspect the Permanent File

Analytical Procedures and Client Risk
Write in your journal your thoughts regarding the following questions:

Who is the client?

What do they do?

Where are they located?

Are they large or small?

Public or private?

Any thoughts regarding what you have read and done so far in this simulation?

Analyze the Preliminary Analytical Review Report:

Are the differences you notice in some of the accounts 
a concern for you?

Which accounts would you concentrate on?

Analyze the Balance Sheet:

Are you concerned about any one of these accounts?

Are they the same accounts you found in the Preliminary Analytical Review Report?

\section{Assess Engagement Risk}

Audit Strategy
Is there a high or unacceptable risk of us getting sued if we take on this client?

Is there a high or unacceptable chance we might get fired if we take on this client?

Will our reputation be tainted?

To Do: Write in your reflective journal your response to each of these three questions.

In addition, write down your thoughts and ideas regarding processes auditors must go through when dealing with their clients and their financial information.

Review the Planning Memo. Focus your understanding of the audit approach the audit team has decided to take. Answer the following questions in your reflective journal:

Based upon your knowledge so far, do you agree with their approach?

Why do you agree with their approach? Or why wouldn't you agree with their approach?

In addition to responding to the above questions, write in your journal the experience you are having with this simulation.

How does the simulation help you understand the responsibilities of an auditor?

Note. Adapted from “An Analysis of Advanced Accounting Students' Perspectives of their Professional Skills Before and After Using Computer-Assisted Instruction,” by S. Lightweis, 2011, ProQuest UMI, p. 127-129.

Before each participant went home, I stressed the fact the learning experience would be totally up to them. Additionally, I explained there are no hard and fast rules from my end as to how they should approach the game. My requirements were to work through the simulation game several times and try their best to answer the journal prompts. The participants had approximately two months to work through these requirements. Communication was through email in case there were any questions on their end or to prompt a participant if they had not entered and exited the simulation after a few days from their last performance report on my end.

Each participant addressed all of the requirements stated in Table 2. The information provided by the participants created a window of their learning experience in working through the simulation game. For the most part, the participants used their knowledge and understanding of auditing to maneuver through the simulation game multiple times. One participant used an auditing textbook, especially when they arrived at the auditing strategy section and wanted some clarification in order to move forward. Additionally, the reflective journal provided written evidence that these participants were able to achieve an understanding of ambiguous situations and challenge their critical thinking, problem-solving, and communication skills. Finally, the reflective journals provided many positive notations. This written evidence demonstrates the need for accounting educators to find learning opportunities, such as this simulation game, to build their student's professional skills.

The only issue each participant stated was that they were disappointed in their experience rating every time they exited the simulation game. The experience rating comes from how well one navigates through the game and 
successfully locates the required information. Additionally, the rating ultimately demonstrates how well one controls efficiency and the audit fee (Lightweis, 2011). Each participant had a different experience in the way they approached the game. For example, one participant was enjoying the conversations they had with the audit manager. But the more time they spent talking with the manager, the more the audit fee increased, along with their experience rating. Also, this participant used the hints provided throughout the game to locate the information. However, the more time spent in this area; the higher the experience rating went, and so did the audit fee. Another participant focused on decreasing the audit fee as they thought it was important in achieving success in the game. The third participant noticed the experience rating was high but concentrated on obtaining the required information. The study was qualitative, therefore while the scores were provided in the performance report; my focus was determining if participants were spending sufficient time in the simulation game. The time spent in the simulation game allowed participants to explain their learning experience and perspectives of their critical thinking, communication, and problem-solving skills.

After receiving a number of performance reports from each participant, I determined the amount of time spent in the simulation would provide enough information for me to analyze. I emailed each participant requesting a postcomputer interview. Table 3 represents the questions that were asked during this interview.

Table 3. Postcomputer interview questions

\section{Questions}

How did you tackle this computer program/simulation?

How well did you understand the information presented in the computer simulation?

How well did you analyze the problems you encountered in the computer simulation?

How you feel regarding your critical thinking skills and ability to do accounting after you now have worked through the computer simulation?

How you feel regarding your communication skills and the ability to do accounting after you now have worked through the computer simulation?

How you feel regarding your problem-solving skills and the ability to do accounting after you now have worked through the computer simulation?

How you feel about learning new accounting concepts on your own?

Note. Adapted from "An Analysis of Advanced Accounting Students' Perspectives of their Professional Skills Before and After Using Computer-Assisted Instruction," by S. Lightweis, 2011, Pro Quest UMI, p. 122.

Overall, the postcomputer interviews revealed important information from each participant. First, instructions in the binder provided both clarity and structure in how all participants approached the simulation. All participants had gone through the game tutorial before they entered the game. All participants were familiar with the accounting and auditing terminology presented throughout the simulation. Participants made a connection between what they learned in their accounting courses as they went through the simulation requirements. Additionally, all participants appreciated the hands-on experience they received and expressed a need for more types of these real-world simulation games to feel comfortable about their professional skills before entering the profession. These participants confirmed their critical thinking and problem-solving skills improved as they worked through the simulation multiple times. Interestingly, all participants stated the importance of having interpersonal communication skills in the accounting profession. The simulation allowed players to observe communication between the client's employees as well as between the auditors. Participants made decisions based upon the discussions occurring within the game. Decision making strengthened participant's critical thinking and problem-solving skills as they maneuvered through the game. Also, participants intentionally learned how to communicate better every time they played the game. Finally, all participants were enthusiastic regarding the learning experience received and wanted to learn more about how to further improve their professional skills in addition to learning more about the profession.

\section{Conclusion}

The purpose of this study was to analyze advanced accounting students' perspectives of their professional skills or critical thinking, communication, and problem-solving skills before and after using a computer simulation. 
This study was conducted to examine the gap between accounting educators and the profession and to provide a possible solution, in the form of a computer simulation, to bridge this gap. The qualitative study provided a number of major themes after analyzing the precomputer and postcomputer interviews, reflective journals, and time spent in the simulation game. The first theme that emerged was participants making a connection between the information provided in the interactive simulation and concepts learned in accounting courses. The second theme that emerged was participants gaining hands-on experience as they worked through the simulation multiple times. Participants' hands on experiences created enthusiasm for learning more about how to improve their skills and seeking additional information regarding the profession. More importantly, participants felt having these hands on experiences improved their professional skills. The fourth theme that emerged was participants who believed their confidence improved after having this learning experience. Building confidence made all participants believe they could be successful in the profession.

Overall, learning about how students feel about their skills levels before and after using a computer simulation added to previous research regarding how to bridge the gap between accounting educators and the profession. Moreover, the study's results allow accounting educators to think about how to add supplemental resources to curriculums to help strengthen students' professional skills as well as build awareness of what it takes to be successful in the profession. In the year 2010 and prior to this study, I researched learning tools on the Internet and found very few computer-assisted instruction programs that supported ambiguous accounting and auditing situations. Additionally, I researched learning experiences that could help improve professional skills in accounting students. I finally located Real Audit ${ }^{\mathrm{TM}}$ and the simulation game met the needs of this study. Therefore, there are several recommendations that can be made based on the positive results of this study. Accounting educators can use their experience as an accounting practitioner and create simulations that depict the challenges in the field. For example, as a cost accounting instructor, a simulation game may include situations faced in the manufacturing industry. The game may include internal financial reports that can be found and analyzed. Another example, as a forensic accounting instructor, a simulation game may include investigations forensic accountants undertake after a crime has been committed in a company. The game may include various interviews required to be conducted and financial evidence to be collected to be presented in a court of law. In these examples, accounting educators can either create these simulations on their own based on their experiences or collaborate with other accounting educators to create simulations. Also, accounting students can design simulation games, as a course-long group project. Each group can present their game to the class to determine if accounting students are being challenged in ambiguous situations and enhancing their professional skills. Finally, state accounting associations and societies provide a venue for accounting educators to collaborate with Certified Public Accountants to determine the current needs of the profession. Perhaps the information gleaned from this collaboration can provide accounting educators with other supplemental tools to assist accounting students in becoming valuable and contributing practitioners after graduation. The more aware accounting students are of the challenges in the profession while attending school, the better prepared they will be to face ambiguous real-life situations and succeed in this complex business world.

\section{Acknowledgments}

This research was supported by Walden University, Minneapolis, Minnesota Reference Number 12-30-10-0383595.

\section{References}

Accounting Education Change Commission. (1990). Objectives of education of accountants: A position statement number one. Issues in Accounting Education, 5(2), 307.

American Accounting Association. (1986). Future of accounting education: Preparing for the expanded profession. Issues in Accounting Education, 1(1), 168-195.

American Institute of Certified Public Accountants. (1998). CPA vision: Focus on the future. NY.

Ballantine, J., Duff, A., \& Larres, P. (2008). Accounting and business students' approaches to learning: A $\begin{array}{llllll}\text { longitudinal study. Journal of Accounting } & \text { Education, } & \text { 26(4), } & 188 .\end{array}$ http://dx.doi.org/10.1016/j.jaccedu.2009.03.001

Cheng, K. (2009). The effect of web-based collaborative learning methods to the accounting courses in technical education. College Student Journal, 43(3), 755-765. Retrieved from http://www.highbeam.com/doc/1G1-206687068.html

Coulson, A., \& Thomson, I. (2006). Accounting and sustainability, encouraging a dialogical approach; integrating learning activities, delivery mechanisms and assessment strategies. Accounting Education, 15(3), 
261-273.

Creswell, J. W. (2007). Qualitative inquiry \& research design: Choosing among five approaches (2nd ed). Thousand Oaks, CA: Sage.

Creswell, J. W. (2003). Research design: Qualitative, quantitative, and mixed methods approaches (2nd ed). Thousand Oaks, CA: Sage.

Damitio, J., \& Schmidgall, R. (2007). What accounting skills do managers value? Strategic Finance, 89(4), $52-53$.

Esmond-Kiger, C., \& Kirch, D. P. (2003). Implementing the business activity model for teaching intermediate accounting: A recipe for success. Management Accounting Quarterly, 4(4), 53-62.

Gammie, B., Gammie, E., \& Cargill, E. (2002). Personal skill development in the accounting curriculum. Accounting Education, 11(1), 63-78. http://dx.doi.org/10.1080/09639280210153272

Guyette, K. (2008). Instructional design model for promoting meaningful learning and problem solving skills for accounting information system students (Doctoral dissertation). Retrieved from ProQuest Digital Dissertations (Publication No. AAT 3311309)

Handy, S. A. (2003). An exploratory study of learner use of a computerized accounting tutorial (Doctoral dissertation). Retrieved from Dissertations \& Theses: Full Text Database. (Publication No. AAT 3071160)

Hurt, B. (2007). Teaching what matters: A new conception of accounting education. Journal of Education for Business, 82(5), 295-299.

International Federation of Accountants. (1996). International education guideline 9-Pre-qualification education assessment of professional competence and experience requirement of professional accountants. NY: International Federation of Accountants.

Jonick, C. A. (1998). A situated business simulation for postsecondary accounting students based on the cognitive apprenticeship model of teaching and learning (Doctoral dissertation). Retrieved from Dissertations \& Theses: Full Text database. (Publication No. AAT 9920048)

Kavanagh, M., \& Drennan, L. (2008). What skills and attributes does an accounting graduate need? Evidence from student perceptions and employer expectations. Accounting \& Finance, 48(2), 279-300. http://dx.doi.org/10.1111/j.1467-629X.2007.00245.x

Lightweis, S. (2011). An analysis of advanced accounting students' perspectives of their professional skills before and after using computer-assisted instruction (Doctoral dissertation). Retrieved from ProQuest LLC. (UMI Number: 3465644)

Marriott, N. (2004). Using computerized business simulations and spreadsheet models in accounting education: A case study. Accounting Education, 13, 55-70. http://dx.doi.org/10.1080/0963928042000310797

Mastracchio, Jr., N. (2007). Value proposition. Journal of Accountancy, 203(6), 82-84. Retrieved from http://www.aicpa.org/pubs/jofa/index.htm

Merriam, S. B. (1998). Qualitative research and case study applications in education. San Francisco: Jossey-Bass.

Morris, M., \& Puttee, C. (2006). Trawling for deeper learning. International Journal of Learning, 13(5), 137-146.

Patton, M. Q. (1987). How to use qualitative methods in evaluation. Newbury Park, CA: Sage.

Sharifi, M., McCombs, G., Fraser, L., \& McCabe, R. (2009). Structuring a competency-based accounting communication course at the graduate level. Business Communication Quarterly, 72(2), 177-199.

Smith, G. L. (2006). Determining differences in the preferred undergraduate accounting curriculum among students, practitioners and educators (Doctoral dissertation). Retrieved from ProQuest Digital Dissertations (Publication No. AAT 3233954)

Springer, C., \& Borthick, A. (2007). Improving performance in accounting: Evidence for insisting on cognitive conflict tasks. Issues in Accounting Education, 22(1), 1-19.

Townsend, C. L. (2006). Basic accounting concepts: Computer based instruction of accounting skills (Doctoral dissertation). Retrieved from Dissertations \& Theses: Full Text database. (Publication No. AAT 1440203)

U.S. Department of Labor. (2009). Occupational outlook handbook (2008-09 ed., O*NET Publication 
Nos.13-2011.00, 13-2011.01, 13-2011.02). Rockville, MD: Author.

U.S. Securities and Exchange Commission. (2009). The securities and exchange commission post-Madoff reforms. Washington, DC: Author.

Valentine, L., \& Ivey, M. (2009). Sustaining ambiguity and fostering openness in the (design) learning environment. Art, Design \& Communication in Higher Education, 7(3), 155-167. http://dx.doi.org/10.1386/adch.7.3.155_1

Yin, R. K. (2009). Case study research: Design and methods (4th ed.). Thousand Oaks, CA: Sage.

\section{Copyrights}

Copyright for this article is retained by the author(s), with first publication rights granted to the journal.

This is an open-access article distributed under the terms and conditions of the Creative Commons Attribution license (http://creativecommons.org/licenses/by/3.0/). 